\title{
Opportunities and challenges of entomopathogenic nematodes as biocontrol agents in their tripartite interactions
}

\author{
Tarique H. Askary ${ }^{1}$ and Mahfouz M. M. Abd-Elgawad ${ }^{2 *}$ (D)
}

\begin{abstract}
Background: The complex including entomopathogenic nematodes (EPNs) of the genera Steinernema and Heterorhabditis and their mutualistic partner, i.e., Xenorhabdus and Photorhabdus bacteria, respectively possesses many attributes of ideal biological control agents against numerous insect pests as a third partner. Despite authenic opportunities for their practical use as biocontrol agents globally, they are challenged by major impediments especially their cost and reliability.

Main body: This review article presents major attributes of EPNs to familiarize growers and stakeholders with their careful application. As relatively high EPN costs and frequently low efficacy are still hindering them from reaching broader biopesticide markets, this is to review the latest findings on EPN strain/species enhancement, improvement of production, formulation and application technology, and achieving biological control of insects from the standpoint of facing these challenges. The conditions and practices that affected the use of EPNs for integrated pest management (IPM) are identified. Besides, efforts have been made to address such practices in various ways that grasp their effective approaches, identify research priority areas, and allow refined techniques. Additionally, sampling factors responsible for obtaining more EPN isolates with differential pathogenicity and better adaptation to control specific pest(s) are discussed.
\end{abstract}

Conclusion: Specific improvements of EPN production, formulation, and application technology are reviewed which may help in their broader use. Other diverse factors that optimize EPNs to constitute a cost-effective, valueadded approach to IPM are also demonstrated.

Keywords: Biocontrol, Entomopathogenic nematodes, Marketing, Sampling, Spatial distribution

\section{Background}

Entomopathogenic nematodes (EPNs) are microorganisms which parasitize, cause disease, and kill the insects. Although the group of EPNs was recently expanded to comprise other nematodes such as certain species in the genus Oscheius (Dillman et al. 2012), only the genera Heterorhabditis and Steinernema are addressed herein

\footnotetext{
* Correspondence: mahfouzian2000@yahoo.com

${ }^{2}$ Plant Pathology Department, National Research Centre, El-Behooth St., Dokki, Giza 12622, Egypt

Full list of author information is available at the end of the article
}

since they have been exclusively developed as EPNs for commercial pest control. This is mainly due to their wide host range, short life cycle, easy in vitro and in vivo mass production, and ability to resist for survival especially under subterranean conditions (Kaya and Stock 1997; Askary and Abd-Elgawad 2017). The third stage juvenile also called infective juvenile (IJ) of EPN is mutually symbiotic with the bacteria Xenorhabdus (in Steinernema) and Photorhabdus (in Heterorhabditis), which produce toxins after entering into the insect host body. The bacterial toxins are mainly responsible for the death 
of host which generally occurs within $48 \mathrm{~h}$ (Kaya and Gaugler 1993). Besides, EPNs are usually non-hazardous, improve the soil quality, compatible with many agrochemicals, biocontrol agents, specific to target pests, and generally non-toxic to beneficial organisms (Askary and Ahmad 2017). Therefore, nematode-bacteria complexes are considered one of the best alternative non-chemical insect pest control.

In this review, the nematode-bacteria-insect interactions were briefly presented to give evidence for the usefulness of optimizing trends for integrated pest management and discussing the different factors affecting their maximum exploitation. Opportunities, conditions, and practices that can enable stakeholders to face challenges for wider exploitation of EPNs as a biological component in integrated pest management (IPM) programs are discussed.

\section{Nematode-bacteria-insect interactions}

The life cycle of Xenorhabdus and Photorhabdus can be divided into 3 phases: (i) phoretic, (ii) pathogenic, and (iii) saprophytic. Phoretic takes place in the nematode host, whereas pathogenic and saprophytic take place in the insect body and insect cadaver, respectively (Koppenhöfer and Gaugler 2009). As the bacteria are released in the hemolymph of host insect, they multiply very rapidly and produce a variety of toxins and hydrolytic exoenzymes. Consequently, the host insect dies, and there is bioconversion of its body into a nutrient soup that aids in growth and reproduction of nematode. During bioconversion, Photorhabdus and Xenorhabdus secrete a variety of small molecule antibiotics that protect the insect cadaver from any contaminating organisms. The interactions under the following subsections were described.

\section{Nematode-bacteria interactions}

Infective juveniles enter into the insect host, reach the hemocoel, and release symbiotic bacteria from their gut. Various toxic and immunosuppressive compounds are released by bacteria that cause septicemia, resulting in death of the host insect (Liao et al. 2017). Steinernema retains the symbiotic bacteria in a specialized vesicle called the receptacle, which is found in the anterior part of the gut, whereas Heterorhabditis lacks this specialized structure and harbors bacteria in their intestinal lumen (Snyder et al. 2007). Axenic nematodes, especially Steinernema species, may kill their hosts by releasing venom which contains a high proportion of proteases (serine carboxypeptidases, trypsins, eukaryotic aspartyl proteases, zinc carboxypeptidases) and protease inhibitors ( $\mathrm{Lu}$ et al. 2017). However, nematode-bacteria symbiotic association is the requirement for potential pathogenicity (Bisch et al. 2015).
Photorhabdus and Xenorhabdus are closely related Gram-negative bacilli, facultative anaerobes, motile, nonspore forming rods from the family Enterobacteriaceae ( $\gamma$-Proteobacteria). One of the major features of the members of family Enterobacteriacae is that they have the ability to reduce nitrate to nitrite, but genera Xenorhabdus and Photorhabdus lack this ability (Snyder et al. 2007; Bisch et al. 2015; Lu et al. 2017). The other unique feature of these two bacterial genera is their phenotypic variation, i.e., the existence of the primary and secondary bacterial form. The environmental stimuli and the role of the switch between the two cell types in the life cycle of EPN symbionts are unclear (Boemare and Akhurst 1988). In a recent report, it has been observed that primary cells, which do not reassociate with nematodes, can live freely in the rhizosphere (Eckstein et al. 2019).

The two distinct characters of the genus Photorhabdus are (i) positive for catalase and (ii) bioluminescence. Xenorhabdus lacks these two features. Photorhabdus are the only light-producing bioluminescent terrestrial bacteria, but the function of this trait in Photorhabdus is still unknown (Sajnaga and Kazimierczak 2020). Both these bacteria are easy to culture in laboratory and grow fast in Luria-Bertani medium, with a doubling time of approximately $2 \mathrm{~h}$. These symbiotic bacteria were isolated and classified for the first time in 1964 (Sajnaga et al. 2018). Yet, recent advances in different aspects of these bacteria such as their evolution, taxonomy, and molecular biology with emphasis on their application to agriculture and medicine have been reviewed (Sajnaga and Kazimierczak 2020; Sajnaga et al. 2018; Osimani et al. 2018).

The success of EPN as biocontrol agent could be improved by developing nematode-bacteria complex that produce proteins necessary for evasion of the host's immune system or nematodes with a short delay in the release of their bacterial symbionts (Kenney and Eleftherianos 2016). The nematode-bacteria symbiosis can be described as a cyclic association that starts and ends with IJs in the soil (Table 1).

Symbiotic association of EPN-bacteria is specific. Each species of Steinernema associates with only one species of Xenorhabdus, but Xenorhabdus may be associated with more than one Steinernema species (Bhat et al. 2020). Xenorhabdus bovienii bacteria have been found symbiotically associated with 14 species of Steinernema, which signifies broad host range of this bacterial species. The nematode hosts of $X$. bovienii belong to two distinct clades of Steinernema (Nadler et al. 2006) distinguished on the basis of the sequences of nuclear and mitochondrial genes: affine-intermedium (clade I) and feltiaekraussei (clade III). Now, S. poinari has also been found symbiotically associated with $X$. bovienii (Sajnaga et al. 2018). Till date, the total number of described species of 
Table 1 Life cycle events in the nematode-bacteria symbiosis

\begin{tabular}{|c|c|c|}
\hline Stage & Nematode life cycle & Bacteria life cycle \\
\hline I & $\begin{array}{l}\text { IJ free living in soil, searches for insect host, finds the } \\
\text { host, and enters into it. }\end{array}$ & Retention of bacteria in the gut of nematode. \\
\hline $\begin{array}{l}\| \\
\text { (early) }\end{array}$ & Recovery in the hemocoel. & $\begin{array}{l}\text { Release of bacteria into insect hemolymph; virulence factors resulting in mortality } \\
\text { of insect host. }\end{array}$ \\
\hline $\begin{array}{l}\text { II } \\
\text { (late) }\end{array}$ & Nematode reproduction. & $\begin{array}{l}\text { Bacteria in stationary phase; production of antibiotics, exo-enzymes, crystal pro- } \\
\text { teins; bioconversion of insect. }\end{array}$ \\
\hline III & New IJs development & Bacteria colonize in the intestine of IJs. \\
\hline
\end{tabular}

Source: Forst and Clarke (2002)

the bacteria Xenorhabdus and Photorhabdus is 26 and 19, respectively (Sajnaga and Kazimierczak 2020).

\section{Insect-bacteria interactions}

After reaching the hemocoel of host insect, Heterorhabditis usually takes $30 \mathrm{~min}$ to release the bacteria, but Steinernema may take several hours to perform such an action (Li et al. 2007). Researchers have demonstrated that ingestion of hemolymph by $S$. carpocapsae triggers the release of Xenorhabdus (Sicard et al. 2004). Xenorhabdus is actively released through the nematode anus, whereas Photorhabdus is egested through the mouth parts of nematode (Ciche et al. 2008). If the insect body is white, the color of its cadaver changes to red when killed by Heterorhabditis, while Steinernema-infected insects become yellow in color (Kaya and Gaugler 1993). Yet, if the cuticle body is not white, the two EPN genera may also affect the color (Fig. 1).

\section{Insect challenge to bacterial infection}

Insect has a possibility to neutralize its parasite before the bacterial challenge. Insects' reactions to nematode infection include the melanization and encapsulation of the parasites with hemocytes. After the infection takes place, proteins are released that recognize and bind surface sugar moeities and trigger further immune responses, e.g., C-type lectins, hemolin, peptidoglycan recognition proteins, and $\beta$-1,3-glucan recognition

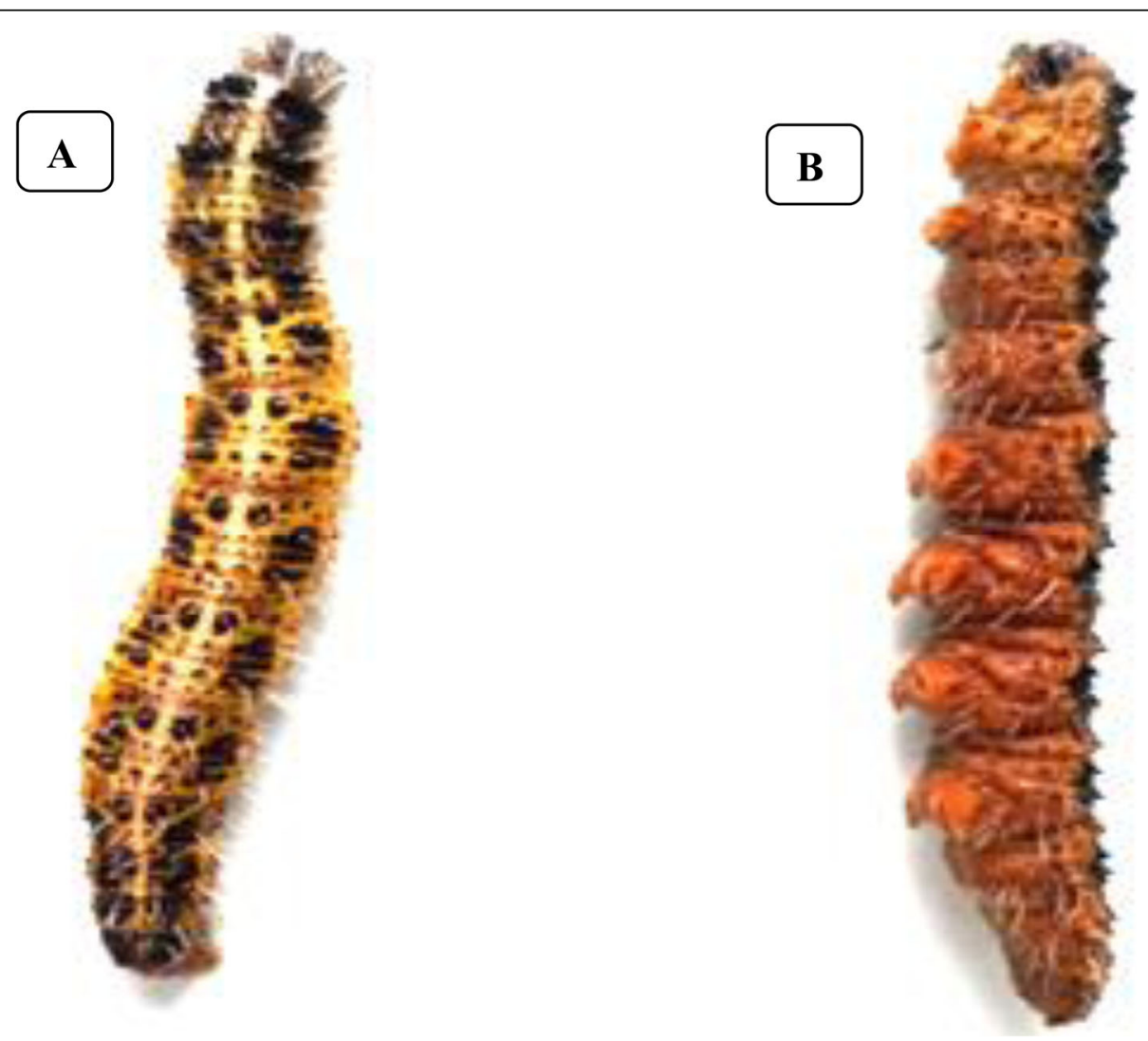

Fig. 1 Dead larvae of cabbage butterfly, Pieris brassicae a killed by Steinernema species, b killed by Heterorhabditis species 
proteins. On the part of insect, the humoral response may be seen as secretion of a variety of peptides and proteins that include lysozyme, cecropins, and attacin which are antimicrobial in nature (Abd-Elgawad 2017). The cellular response includes phagocytosis by hemocytes or the formation of hemocyte aggregates (nodules), which are controlled by the eicosanoid pathway (Lavine and Strand 2002). Nodules and other sites of infection are usually associated with a rapid darkening due to the synthesis of insoluble melanin which clumps around the bacteria making them immobile and depriving them from nutrients. This melanization is initiated through the phenoloxidase cascade. Prophenoloxidase is a proenzyme which is found in the hemolymph of insect and activated by proteolytic cleavage to form phenoloxidase which initiates melanin synthesis, melanotic encapsulation, and the release of microbicidal reactive intermediates (Zhao et al. 2007). In contrast, there are numerous cases wherein Photorhabdus species have proved acceptable in insect pest control (Abd-Elgawad 2017).

\section{Bacteria counter to insect immune response}

Despite the abovementioned mechanisms adopted by host insect, nematodes and their symbiotic bacteria often become able to inhibit the insect's immune system, suppress the melanization process, and depress the antimicrobial response (Lalitha et al. 2018). The host expressions of anti-microbials, viz., lysozyme and cecropins, are inhibited by Xenorhabdus species (Park et al. 2007). Bacterial proteases which target the antimicrobials have also been implicated in evasion of the insect immune response. In Photorhabdus, a serralysin-type protease PrtA has been observed to target proteins with immune-related function under in vitro conditions (Felföldi et al. 2009).

\section{Nematode-insect interactions}

Finally, some EPNs especially from the genus Steinernema can infect and kill insect hosts even in the absence of their mutualistic bacteria, at least in laboratory conditions (Abd-Elgawad 2017). In fact, EPNs lacking mutualistic bacteria can offer rational tools to study the molecular basis of their parasitism on host insects and better characterize the insect host immune factors against nematode infections. Yet, such a study is not in the scope of this review.

\section{Opportunities}

The target insects of EPNs comprise a quite wide range of pests that belong to foliar, soil surface, cryptic, and subterranean habitats. Some of the most commercially produced and successfully applied nematodes include Steinernema carpocapsae, S. feltiae, S. kraussei, S. glaseri, $S$. riobrave, Heterorhabditis bacteriophora, and $H$. megidis. Their ease of production through an inexpensive liquid culture could offer them a unique opportunity to be sold at relatively lower costs (Askary and Ahmad 2017). For example, both $H$. bacteriophora and $H$. megidis obtained a major market share in the control of the black vine weevil, Otiorhynchus sulcatus which is considered a major pest problem of yew, rhododendron, and many other nursery plants. Hence, $95 \%$ of German tree nurseries had switched to nematodes as the major control agent of this pest (Ehlers 2007). Another good market in Europe was developed via in vitro liquid mass production of $H$. bacteriophora for the turf pests. Although this nematode species was not able to produce a knock-down effect against turf grass grubs in Germany, it was able to achieve up to $95 \%$ control after a period of 8 weeks. Thus, there is not only a market in professional lawn care and golf but also in the home and gardening market. The nematodes were packed in colorful boxes and flyers to attract customers in the non-professional sector (Ehlers 2007). In addition, using the best EPNhost matching enabled successful commercialization of S. feltiae products in the sciarid market for mushroom producers. The best EPN-host matching extended significant sales that include $S$. riobrave for Diaprepes root weevils, S. carpocapsae for the Hylobius root weevils, $S$. glaseri for grubs, S. kraussei for the spruce web-spinning sawfly, and Cephaleia abietis and Steinernema scapterisci for mole crickets (Shapiro-Ilan et al. 2020).

Fortunately, the COST Actions 812, 819, and 850 had produced a network of scientists in public and private organizations within Europe, and these contacts were valuable for EPN product introduction, primarily all over Europe and smaller amounts to the USA and Canada as well as other countries. In fact, more EPN projects and programs are now underway which will hopefully result in getting more and diverse EPN markets in different climatic zones.

Admittedly, effective practical usage of EPNs on a commercial scale has experienced both successes and failures. Yet, most of the family owned small to medium enterprises are still operating as a cottage industry. In order to optimize their productivity, they produce microorganisms other than EPNs, for plant protection either for other companies or to develop their own products. Thus, the perspectives are good that such EPN-producing companies will one day pay back the investment as they do not depend on only one product; diversification of contract production into other sectors like aquaculture and cosmetic industries will enhance the stability of the company and the probability of success (Ehlers 2007; Askary and Abd-Elgawad 2017). Therefore, patience and hard work with further gradually acquired knowledge on optimal implementation strategies will expand the practical adoption of EPNs. 
In addition to the above-mentioned attractive attributes as bio-insecticides, EPNs have proven as a relevant biological model in the fields of soil ecology, symbiotic relationships, and evolutionary biology (Campos-Herrera et al. 2012). A direct injection of Xenorhabdus species without their nematode host has been found highly pathogenic to insects (McMullen et al. 2017). Utilization of Xenorhabdus and Photorhabdus bacteria has a good scope for biological control in agroforestry industries (McMullen et al. 2017), as mosquito control repellents and feeding-deterrents (Kajla et al. 2019), and in medical applications as a response to the need for novel antibiotics (Xue et al. 2018). Xenorhabdus species have a broad spectrum of genetic diversity, and they differ in the virulence phenotype, which is determined by a wide variety of secreted bioactive components necessary for invasion, colonization, and use of the insect cadaver as a food source. Analyses of different Xenorhabdus strains may be a source in the discovery of novel natural products such as antibiotics, toxins, adhesins, hemolysins, proteases, and lipases (Murfin et al. 2015). With the increase in the number of Xenorhabdus strains, their role in medicine and pharmacy becomes important. However, lack of sufficient information regarding the diversity of Xenorhabdus within the species limits the application of these bacteria. Moreover, although many valid species of Steinernema and Heterorhabditis have been described (e.g., Shapiro-Ilan et al. 2020), only 13 of these identified species have been commercialized till now (Koppenhöfer et al. 2020a). This fact provides a scope to exploit the other species. Further studies on the diversity of the mutualistic bacteria should also be listed in priority areas.

\section{Tactics and strategies to meet challenges for improving EPN exploitation}

Despite all abovementioned positive attributes of EPNs and their mutualistic partner against the insect pests as a third partner, certain challenges are still hindering them from reaching broader biopesticides markets. Main issues that negatively affect wider applications of EPNs are high product price, limited product demand, insufficient knowledge of the end user, and low efficiency (Askary et al. 2017). Since these issues are interrelated, solving one of them can positively affect another issue (Abd-Elgawad 2019). For example, low efficiency may result in limited product demand. Also, effective-cost application can have an impact on EPN efficiency. Crucial scopes that can face such challenges and attain substantial progress in broader EPN marketing comprise EPN strain/species enhancement, improvement of production, formulation and application technology especially toward aboveground applications, conservation biocontrol, and other diverse factors. Most of these challenges have been addressed (Shapiro-Ilan et al. 2020). However, in the present review, we have tried to address them with an aim to solve such issues in various ways that grasp their effective approaches, identify research priorities, and highlight better techniques.

\section{EPN strain/species enhancement}

A native EPN species is more adaptive to local environmental conditions and has been found very successful in controlling local insect pests (Bhat et al. 2019). However, it is also well-established that EPN efficacy can be enhanced via discovery of new strain/species or nematode breeding/genetic engineering. The latter can be attained through direct selection, hybridization, or genetic manipulation (Baiocchi et al. 2017). On the other hand, if EPN species/strains that are already available do not meet efficacy requirements, a strict method for amelioration is to simply find a superior nematode strain or species. This is generally fulfilled by carrying out surveys, followed by Koch's postulates, and subsequent virulence screening of EPNs that have been isolated in comparison to existing stocks (Shapiro-Ilan et al. 2020). Admittedly, the significant strain improvements made to EPN biocontrol have historically come through the discovery of new species/strains and then by classical genetics. Therefore, a few aspects to optimize EPN sampling and get more species/strains are addressed herein.

\section{Functional sampling}

The extreme diversity of EPN sampling makes any generalization from a given case-study difficult. However, based on what has already been done in many related EPN surveys, it is clear that the percentage of samples positive for EPN is relatively low (Glazer 2015). This general decline in the positive samples demonstrates the desperate need to increase the number of nematode-positive samples whenever possible, and also by exploring untouched geographical areas and climatic conditions (Bhat et al. 2020). Hence, a hypothesis of rational sampling was recently tested (Abd-Elgawad 2020). It is based on combining four factors, i.e., advantageous sampling approach, site and time targeting, and utilizing repeated extraction cycles. In this respect, systematic and stratified random sampling from weed-infested soil under tree canopy during an outburst season of insect reproduction was adopted, and multiple Galleria-baiting technique was carried out. Consequently, as high as $61.7 \%$ of soil samples were EPN-positive. Collectively, these factors could successfully be used to significantly optimize sampling results (Abd-Elgawad 2020). Such a rational sampling could detect more EPN isolates from citrus orchards and allow applying different indices of dispersion to study their spatial distribution pattern. In this respect, contrary to the commonly used single 
Galleria cycle to check for nematode presence, multiple cycles of the Galleria-baiting with adequate last instar G. mellonella larvae per sample/cup were utilized in each cycle. The technique demonstrates that a single extraction cycle of the Galleria-bait method, used in many other surveys, is often insufficient for determining the presence of nematodes in particular soil samples or for extracting all the nematodes from soil samples. More importantly, it is expected that the data obtained in this manner can comprise EPN species/strains with differential pathogenicity among them. Clearly, this technique should be utilized to obtain EPN with high recovery value and possible differential pathogenicity.

\section{The size of sampling unit}

Nematologists have been using various sizes of sampling units. Obviously, if the area of a sampling unit is much larger or much smaller than the average size of EPNinfective juvenile aggregations and their clumps are regularly or randomly distributed; then, their population pattern is apparently random; factual non-randomness is not detected. Thus, when the size of the soil sampling unit steadily increase, the apparent EPN dispersion of a contagious population becomes random, contagious, and finally regular (Abd-Elgawad 2019). A standard size of sampling units is needed for accurate EPN-distribution which would help in grasping their best application patterns.

\section{Improvement of production, formulation, and application technology}

The production, formulation, and application technology represents one of the headlines that can significantly contribute in solving the main impediments for broader commercialization of EPNs (Shapiro-Ilan et al. 2020). Merits and demerits of each EPN production technology have been demonstrated (e.g., Shapiro-Ilan et al. 2014b). Issues of production concern comprise capital outlay, labor, technical expertise, nematode quality, and cost efficiency. In valuing the advantages of the methods among these issues, in vitro liquid culture and in vivo production are the extremes, and in vitro solid culture is intermediate between them. For instance, the level of capital outlay, production volume, and expertise requirement is the lowest for in vivo production (Shapiro-Ilan et al. 2014b). The major economic limitations for in vivo production are the cost of insects and labor. These issues have been addressed by mechanizing the process comprising insect production, inoculation, harvest, and packaging (Shapiro-Ilan et al. 2020). Moreover, adding host-cadaver macerate or EPN pheromones to EPN products could enhance desired behavior such as increased EPN dispersal for better pest control. On the other hand, a merit to in vivo set is the ease of adapting the process to new/different EPN species. Generally, the process can remain the same except for some slight modifications (e.g., temperature regimes). Since EPN products remain cost prohibitive in many markets, additional advances to increase production efficiency and to reduce costs are required. Hence, scaling up of in vivo method was suggested in developing countries like Egypt (Abd-Elgawad 2017). Basically, a small harvester and separator have been built for in vivo production. The production steps are infection, incubation, harvest, separation, and clean up (Askary and Ahmad 2017). Improvements are being made continuously in inoculation, harvest techniques, post-harvest nematode concentration, and cleaning of the system (Abd-Elgawad 2017). Each step has specific requirements, which must be optimized separately to ensure adaptation of a specific nematode to its best matching insect host. All parameters in the abovementioned 5 steps may be further optimized as a cottage industry. In this context, harvester dimensions and harvesting parameters require optimization for each specific host/nematode system for scaling up. Admittedly, such a local nematode production system can eliminate or reduce transport, packaging, formulation, and storage costs while providing fresh, locally adapted and effective strains of EPNs. Thus, this production system offers proper matching of nematode-host and ensures suitable affordability especially in developing countries for specific indigenous strain rather than "one size fits all" approach used elsewhere (Abd-Elgawad 2017). Factually, the system suits regions which lack the capital and expertise to develop a biopesticide production industry. The keys should be local small-batch custom production and quick turnover which can provide high-quality products (Shapiro-Ilan et al. 2020).

The highest production volume and least costs of EPNs are attained via liquid culture. Yet, lower EPN quality in terms of reduced host-finding, virulence, or longevity in liquid culture relative to in vivo production has been reported, though in other cases no differences were detected due to culture method (Shapiro-Ilan et al. 2020). Admittedly, media components and bioreactor parameters should be greatly considered for fine tuning because they can significantly affect EPN yields and quality in fermentation process of in vitro production.

Formulations of EPNs should be enhanced for easier handling, effective application, increased environmental persistence, and longer stability and shelf life. Formulations for aqueous EPN application vary widely and can be applied efficiently with practically all types of cultural application equipment. Nevertheless, the used equipment should properly comply with the cropping ecosystem. Therefore, a variety of parameters should be optimized in each case including nozzle/dripper type, 
volume, agitation, pressure and recycling time, environmental conditions, and EPN distribution pattern. In all cases, suitable agitation during application is critical. Other methods of formulation and application that could conceivably be expanded include baits, applying the nematodes in their infected hosts, microjet irrigation systems, trunk-sprayers, and subsurface injection (Shapiro-Ilan et al. 2020).

Foliage pests represent difficult targets for aqueous application of EPNs. Progress in this area was recently updated and should be exploited (Shapiro-Ilan et al. 2020). For instance, a surfactant and polymer formulation has been utilized to increase leaf coverage and improve aboveground application efficacy. Application of a sprayable fire gel could better control the lesser peach tree borer, Synanthedon pictipes. Other formulations developed for aboveground application include those based on chitosan, wood flour foam, or other adjuvants. Improved application equipment and advanced application techniques are being applied to enhance EPN efficacy to control the scarab beetle, Temnorhynchus baal, in strawberry fields. For this purpose, a device is used to pump the nematode suspension almost evenly at all drippers during trickle irrigation. Local heterorhabditid nematode strains that best match $T$. baal control (Shehata et al. 2019) could further optimize the techniques. On the other hand, splitting nematode applications in two at half rates approximately 5-10 days apart should be examined. Generally, more splitting may be done with an end in view that the applications synchronize with the most EPN-susceptible stage(s) of insect pest(s). These highly susceptible stages lend themselves the most for control by EPNs (Koppenhöfer et al. 2020b).

\section{Conservation biocontrol}

Biological pest control is often based on inundative release of mass-produced EPNs. However, weak points in this technique are pest control efficacy and cost of repeated application, often attributed to the poor establishment of EPNs. Additional approaches that decrease exposure to harmful biotic or abiotic stressors or increase EPN persistence, reproduction, or virulence will expand biocontrol efficacy (Abd-Elgawad 2017; ShapiroIlan et al. 2020). For example, EPN persistence can be improved through making the soil environment more conducive to EPN survival such as setting adequate soil $\mathrm{pH}$ or adding suitable soil amendments, e.g., mulch or crop residues (Campos-Herrera et al. 2019).

Moreover, EPNs utilize phased infectivity to bridge periods of time of environmental stress and lack of host availability. This supports the idea that these survival mechanisms are genetically encoded and are easily lost under conditions of continuous rearing practiced by some commercial producers. So, more emphasis should be placed on the long-term establishment of the EPN in the soil profile for expanded pest suppression through pest recycling and the selection of an EPN population which retains the genetic coding for extended persistence under low host density and unfavorable environmental conditions. In order for EPNs to retain their adaptation for field survival, several approaches can be utilized to help to keep such genes in laboratory culture. These include re-isolation from the field, establishing "wild populations" in easily accessible areas, and rational laboratory culturing to possess persistence (Shields 2015). Additionally, factors which affect EPN persistence and recycling levels such as host density, nematode species/strain, soil type, and ground cover should be considered (Shapiro-Ilan et al. 2020).

\section{Other diverse factors to widen EPN utilization}

Scientists should further advance biopesticides to occupy new positions. For example, IPM of Caribfly, Anastrepha suspensa, to boost guava production was established on adequate identification of conditions and practices that enhance effective application of EPNs using a costeffective technique (Heve et al. 2018). Another avenue to wider utilization of EPNs is to control veterinary pests such as the gray flesh flies Parasarcophaga aegyptiaca as one of the external parasites, an important pest with wide distribution and significant role in causing serious diseases such as myiasis, which can invade various tissues of man and animals. Steinernema riobrave and $H$. floridensis might also be used as part of an integrated approach to control Yucatan strain of Rhipicephalus microplus (Canestrini) resistant to various classes of acaricides (Singh et al. 2019). These relatively neglected specialties need further applied research to maintain animal health using properly safe and environmentally friendly approaches. Moreover, applying the nematodesymbiotic bacteria or their byproducts to control arthropod pests (Abd-Elgawad 2017) or plant pathogens (Shapiro-Ilan et al. 2014a) have shown positive results that require following up to develop the methodology. Also, metabolites derived from Xenorhabdus and Photorhab$d u s$ bacteria have been recorded to suppress various serious plant pathogens in genera including Armillaria, Monilinia, Phytophthora, and Venturia (Shapiro-Ilan et al. 2020).

Other economical concepts may contribute to cut the costs short. The EPN producer can act at the same time as the distributor. Furthermore, the producer may nominate some of its employees with experience in EPN application (Abd-Elgawad 2017). Factually, those experts can recognize EPN issues such as the viability of IJs, contamination, and nematode fate/persistence. Admittedly, being responsible for producing, distributing, applying, and following up EPNs all by the same company 
will reduce costs and increase profit margins. Such a multiple service offered by the producer seems more attractive to the growers than an employee/company with a single job.

Clearly, in order to optimize their benefits, EPNs should operate in IPM programs in ways that make them complimentary or superior to chemical pest management and/or other agricultural inputs (Stevens and Lewis 2017). So, full and relevant lists of bio-insecticides with EPN species/strains that can act synergistically or additively with other agricultural inputs should be available. Strictly speaking, such lists should satisfy challenges to identify and broadly disseminate conditions under which the EPNs constitute a cost-effective, value-added approach to IPM. All the abovementioned lines of thinking represent current challenges that are substantial to seize more significant share of EPNs in the pesticide markets.

\section{Conclusions}

Entomopathogenic nematodes and their mutualistic bacteria are commercially used as safe alternatives to chemical insecticides. Opportunities that enabled their development and implementation for the control of insect pests should be better exploited. There are still important factors such as their cost and efficacy which relegate EPNs to niche pesticide markets. Therefore, the relatively inexpensive and wider practical use of EPNliquid culture could offer them a unique opportunity to be sold at fairly low costs. On the other hand, in vivo local production of EPNs can eliminate or reduce transport, packaging, formulation, and storage costs while providing fresh, locally adapted, and effective strains of biocontrol agents to develop a biopesticide cottage industry in regions, which lack the capital and expertise. Furthermore, a key factor regarding in vivo production of EPNs via scaling-up system is satisfying the EPN product demands even in continuous small quantities with prompt turnover of capital. Additionally, the best nematode-host matching should play significant roles for their use. Clearly, every possible opportunity to optimize relevant EPN research areas and to better utilize as biopesticides should be exploited. These may include EPN strain/species enhancement via rational and standardization of EPN sampling. Further improvement of production, formulation, and application technology could be practiced. Molecular handling of EPNs should examine non-stability of beneficial traits preferably via detecting chemical markers of beneficial genes. Awareness-raising of growers and stakeholders for broader dissemination of conditions under which the EPNs constitute a cost-effective, value-added approach to IPM should be better addressed.

\section{Abbreviations \\ EPNs: Entomopathogenic nematodes; IJ: Infective juveniles; IPM: Integrated pest management}

\section{Acknowledgements}

The authors are thankful to the Head of Division of Entomology, Faculty of Agriculture, SKUAST-K, for providing necessary facilities required to conduct this study. The view presented herein was supported in part by the US-Egypt Project cycle 17 (no. 172) entitled "Preparing and evaluating IPM tactics for increasing strawberry and citrus production." The study was also supported in part by the NRC In-house project No. 12050105 entitled "Pesticide alternatives against soil-borne pathogens and pests attacking economically important solanaceous crops".

\section{Authors' contributions}

All authors participated in the development and implementation of the reviewing plan and subsequently written it. The first author TA discussed the different parts of the article with MA and finalized the manuscript. All authors have read and approved the final manuscript.

\section{Funding}

Financial support was partially made by both the US-Egypt Project related to Science and Technology Development Fund via Project cycle 17 (no. 172) and National Research Centre, Egypt (In-house project No. 12050105).

\section{Availability of data and materials}

The datasets used and/or analyzed during the current study are available from the corresponding author on reasonable request.

Ethics approval and consent to participate

Not applicable

Consent for publication

Not applicable

\section{Competing interests}

The authors declare no competing interests.

\section{Author details}

${ }^{1}$ Division of Entomology, Faculty of Agriculture, Sher-e-Kashmir University of Agricultural Sciences and Technology of Kashmir, Wadura, Sopore, Jammu and Kashmir 193201, India. ${ }^{2}$ Plant Pathology Department, National Research Centre, El-Behooth St., Dokki, Giza 12622, Egypt.

Received: 3 December 2020 Accepted: 17 February 2021

Published online: 24 February 2021

\section{References}

Abd-Elgawad MMM (2017) Toxic secretions of Photorhabdus and their efficacy against crop insect pests. In: Abd-Elgawad MMM, Askary TH, Coupland J (eds) Biocontrol agents: entomopathogenic and slug parasitic nematodes. CAB International, UK, pp 231-260

Abd-Elgawad MMM (2019) Towards optimization of entomopathogenic nematodes for more service in the biological control of insect pests. Egypt J Biol Pest Cont 29:77. https://doi.org/10.1186/s41938-019-0181-1

Abd-Elgawad MMM (2020) Can rational sampling maximise isolation and fix distribution measure of entomopathogenic nematodes? Nematology 22(8): 907-916. https://doi.org/10.1163/15685411-00003350

Askary TH, Abd-Elgawad MMM (2017) Beneficial nematodes in agroecosystem: a global perspective. In: Abd-Elgawad MMM, Askary TH, Coupland J (eds) Biocontrol agents: entomopathogenic and slug parasitic nematodes. CAB International, UK, pp 3-25

Askary TH, Ahmad MJ (2017) Entomopathogenic nematodes: mass production, formulation and application. In: Abd-Elgawad MMM, Askary TH, Coupland (eds) Biocontrol agents: entomopathogenic and slug parasitic nematodes. CAB International, UK, pp 261-286

Askary TH, Nermut J, Ahmad MJ, Ganai MA (2017) Future thrusts in expanding the use of entomopathogenic and slug parasitic nematodes in agriculture. In: Abd-Elgawad MMM, Askary TH, Coupland J (eds) Biocontrol agents: entomopathogenic and slug parasitic nematodes. CAB International, UK, pp 620-627 
Baiocchi T, Abd-Elgawad MMM, Dillman AR (2017) Genetic improvement of entomopathogenic nematodes for enhanced biological control. In: AbdElgawad MMM, Askary TH, Coupland J (eds) Biocontrol agents: entomopathogenic and slug parasitic nematodes. CAB International, UK, pp 505-517

Bhat AH, Askary TH, Ahmad MJ, Suman A, Chaubey AK (2019) Description of Heterorhabditis bacteriophora (Nematoda: Heterorhabditidae) isolated from hilly areas of Kashmir valley. Egypt J Biol Pest Cont 29:96. https://doi.org/1 0.1186/s41938-019-0197-6

Bhat AH, Chaubey AK, Askary TH (2020) Global distribution of entomopathogenic nematodes, Steinernema and Heterorhabditis. Egypt J Biol Pest Cont 30:31. https://doi.org/10.1186/s41938-020-0212-y

Bisch G, Pagès S, McMullen JG, Stock SP, Duvic B, Givaudan A, Gaudriault S (2015) Xenorhabdus bovienii CSO3, the bacterial symbiont of the entomopathogenic nematode Steinernema weiseri, is a non-virulent strain against lepidopteran insects. J Inverteb Pathol 124:15-22

Boemare NE, Akhurst RJ (1988) Biochemical and physiological characterization of colony form variants in Xenorhabdus spp. (Enterobacteriaceae). J Gen Microbiol 134:751-761

Campos-Herrera R, Barbercheck M, Hoy CW, Stock SP (2012) Entomopathogenic nematodes as a model system for advancing the frontiers of ecology. J Nematol 44:162-176

Campos-Herrera R, Stuart RJ, Pathak E, FE EL-B, Duncan LW (2019) Temporal patterns of entomopathogenic nematodes in Florida citrus orchards: evidence of natural regulation by microorganisms and nematode competitors. Soil Biol Biochem 128:193-204

Ciche TA, Kim KS, Kaufmann-Daszczuk B, Nguyen KC, Hall DH (2008) Cell invasion and matricide during Photorhabdus luminescens transmission by Heterorhabditis bacteriophora nematodes. Appl Environ Microbiol 74:22752287

Dillman AR, Chaston JM, Adams BJ, Ciche TA, Goodrich-Blair H, Stock SP, Sternberg PW (2012) An entomopathogenic nematode by any other name. PLOS Pathog. 8(3):e1002527. https://doi.org/10.1371/journal.ppat.1002527

Eckstein S, Dominelli N, Brachmann A, Heermann R (2019) Phenotypic heterogeneity of the insect pathogen Photorhabdus luminescens: insights into the fate of secondary cells. Appl Environ Microbiol 85(22). https://doi. org/10.1128/AEM.01910-19

Ehlers R-U (2007) Entomopathogenic nematodes: from science to commercial use. In: Vincent C, Stanislaw M, Lazarovits G (eds) Biological control: a global perspective. CAB International, UK, pp 136-151

Felföldi G, Marokházi J, Képiró M, Venekei I (2009) Identification of natural target proteins indicates functions of a serralysin-type metalloprotease, PrtA, in antiimmune mechanisms. Appl Environ Microbiol 75:3120-3126

Forst S, Clarke D (2002) Bacteria-nematode symbiosis. In: Gaugler R (ed) Entomopathogenic nematology. CAB International, UK, pp 57-77

Glazer I (2015) Improvement of entomopathogenic nematodes: a genetic approach. In: Campos-Herrera R (ed) Nematode pathogenesis of insects and other pests. Springer, Switzerland, pp 29-55

Heve WK, El-Borai FE, Johnson EG, Carrillo D, Crow WT, Duncan LW (2018) Responses of Anastrepha suspensa, Diachasmimorpha longicaudata, and sensitivity of guava production to Heterorhabditis bacteriophora in fruit fly integrated pest management. J Nematol 50:261-272

Kajla MK, Barrett-Wilt GA, Paskewitz SM (2019) Bacteria: a novel source for potent mosquito feeding-deterrents. Sci Adv 5(1). https://doi.org/10.1126/sciadv.aa u6141.2019.eaau6141

Kaya HK, Gaugler R (1993) Entomopathogenic nematodes. Ann Rev Entom 38: $181-206$

Kaya HK, Stock SP (1997) Techniques in insects nematology. In: Lacey L (ed) Manual of techniques in insect pathology. Biol Tech Ser, Acad Pub, USA, pp 281-324

Kenney E, Eleftherianos I (2016) Entomopathogenic and plant pathogenic nematodes as opposing forces in agriculture. Int J Parasitol 46:13-19

Koppenhöfer AM, Shapiro-llan DI, Hiltpold I (2020a) Entomopathogenic nematodes in sustainable food production. Front Sustain Food Syst 4:125. https://doi.org/10.3389/fsufs.2020.00125

Koppenhöfer HS, Gaugler R (2009) Entomopathogenic nematode and bacteria mutualism. In: White J, Torres M (eds) Defensive mutualism in microbial symbiosis. CRC Press, Boca Raton, Florida, pp 99-116

Koppenhöfer HS, Kostromytska OS, Shaohui W (2020b) Optimizing the use of entomopathogenic nematodes for the management of Listronotus maculicollis (Coleoptera: Curculionidae): split applications and combinations with imidacloprid. Crop Protect 137:105229. https://doi.org/10.1016/j.cropro.2 020.105229

Lalitha K, Karthi S, Vengateswari G, Karthikraja R, Perumal P, Shivakumar MS (2018) Effect of entomopathogenic nematode of Heterorhabditis indica infection on immune and antioxidant system in lepidopteran pest Spodoptera litura (Lepidoptera: Noctuidae). J Parasit Dis 42:204-211

Lavine MD, Strand MR (2002) Insect haemocytes and their role in immunity. Insec Biochem Molec 32:1295-1309

Li XY, Cowles RS, Cowles EA, Gaugler R, Cox-Foster DL (2007) Relationship between the successful infection by entomopathogenic nematodes and the host immune response. Int J Parasitol 37:365-374

Liao C, Gao A, Li B, Wang M, Shan L (2017) Two symbiotic bacteria of the entomopathogenic nematode Heterorhabditis spp. against Galleria mellonella. Toxicon 127:85-89

Lu D, Sepulveda C, Dillman AR (2017) Infective juveniles of the entomopathogenic nematode Steinernema scapterisci are preferentially activated by cricket tissue. PLoS ONE 12(1):e0169410. https://doi.org/10.1371/ journal.pone.0169410 2017 e0169410

McMullen JG, McQuade R, Ogier J-C, Pages S, Gaudriault S, Stock SP (2017) Variable virulence phenotype of Xenorhabdus bovienii (gamma-Proteobacteria. Enterobacteriaceae) in the absence of their vector hosts. Microbiol. 163:510522

Murfin KE, Whooley AC, Klassen JL, Goodrich-Blair H (2015) Comparison of Xenorhabdus bovienii bacterial strain genomes reveals diversity in symbiotic functions. BMC Genom 16:889. https://doi.org/10.1186/s12864-015-2000-8

Nadler SA, Bolotin E, Stock SP (2006) Phylogenetic relationships of Steinernema Travassos, 1927 (Nematoda: Cephalobina: Steinernematidae) based on nuclear, mitochondrial and morphological data. Syst Parasitol 63:161-181

Osimani A, Milanović V, Cardinali F, Garofalo C, Clementi F, Pasquini M, Riolo P, Ruschioni S, Isidoro N, Loreto N, Franciosi E, Tuohy K, Petruzzelli A, Foglini M, Gabucci C, Tonucci F, Aquilanti L (2018) The bacterial biota of laboratoryreared edible mealworms (Tenebrio molitor L.): from feed to frass. Int J Food Microbiol 272:49-60

Park Y, Herbert EE, Cowles CE, Cowles KN, Menard ML, Orchard SS, Goodrich-Blair $\mathrm{H}$ (2007) Clonal variation in Xenorhabdus nematophila virulence and suppression of Manduca sexta immunity. Cell Microbiol 9:645-656

Sajnaga E, Kazimierczak W (2020) Evolution and taxonomy of nematodeassociated entomopathogenic bacteria of the genera Xenorhabdus and Photorhabdus: an overview. Symbiosis 80:1-13

Sajnaga E, Kazimierczak W, Skowronek M, Lis M, Skrzypek T, Waśko A (2018) Steinernema poinari (Nematoda: Steinernematidae): a new symbiotic host of entomopathogenic bacteria Xenorhabdus bovienii. Arch Microbiol 200:13071316

Shapiro-llan D, Hazir S, Glazer I (2020) Advances in use of entomopathogenic nematodes in integrated pest management. In: Kogan M, Heinrichs EA (eds) Integrated management of insect pests: current and future developments. Burleigh Dodds Science Publication, UK, pp 1-30

Shapiro-Ilan DI, Bock CH, Hotchkiss MW (2014a) Suppression of pecan and peach pathogens on different substrates using Xenorhabdus bovienii and Photorhabdus luminescens. Biol Cont 77:1-6

Shapiro-llan DI, Han R, Qiu X (2014b) Production of entomopathogenic nematodes. In: Morales-Ramos J, Rojas G, Shapiro-llan DI (eds) Mass production of beneficial organisms: invertebrates and entomopathogens. Academic Press, New York, pp 321-356

Shehata IE, Hammam MMA, El-Borai FE, Duncan LW, Abd-Elgawad MMM (2019) Comparison of virulence, reproductive potential, and persistence among local Heterorhabditis indica populations for the control of Temnorhynchus baal (Reiche \& Saulcy) (Coleoptera: Scarabaeidae) in Egypt. Egypt J Biol Pest Cont 29:32. https://doi.org/10.1186/s41938-019-0137-5

Shields EJ (2015) Utilizing persistent entomopathogenic nematodes in a conservation or a more classical biological control approach. In: CamposHerrera R (ed) Nematode pathogenesis of insects and other pests. Springer, Switzerland, pp 165-184

Sicard M, Ferdy JB, Pages S, Le Brun N, Godelle B, Boemare N, Moulia C (2004) When mutualists are pathogens: an experimental study of the symbioses between Steinernema (entomopathogenic nematodes) and Xenorhabdus (bacteria). J Evol Biol 17:985-993

Singh NK, Goolsby JA, Jyoti J, Shapiro-llan DI, Miller RJ, Pérez de León AA (2019) Comparative efficacy of entomopathogenic nematodes against a multiacaricide resistant strain of southern cattle fever tick, Rhipicephalus microplus. Southwest Entomol 44:143-153 
Snyder H, Stock PS, Kim S-K, Flores-Lara Y, Forst S (2007) New insight into the colonization and release process of Xenorhabdus nematophila and the morphology and ultrastructure of the bacterial recepacle of its nematode host, Steinernema carpocapsae. Appl Environ Microb 73:5338-5346

Stevens G, Lewis E (2017) Status of entomopathogenic nematodes in integrated pest management strategies in the USA. In: Abd-Elgawad MMM, Askary TH, Coupland J (eds) Biocontrol agents: entomopathogenic and slug parasitic nematodes. CAB International, UK, pp 289-311

Xue Y, Wang M, Zhao P, Quan C, Li X, Wang L, Gao W, Li J, Zu X, Fu D, Feng S, Li P (2018) Gram-negative bacilli-derived peptide antibiotics developed since 2000. Biotechnol Lett 40:1271-1287

Zhao PC, Li JJ, Wang Y, Jiang HB (2007) Broad-spectrum antimicrobial activity of the reactive compounds generated in vitro by Manduca sexta phenoloxidase. Insect Biochem Molec 37:952-959

\section{Publisher's Note}

Springer Nature remains neutral with regard to jurisdictional claims in published maps and institutional affiliations.

\section{Submit your manuscript to a SpringerOpen ${ }^{\circ}$ journal and benefit from:}

- Convenient online submission

- Rigorous peer review

- Open access: articles freely available online

High visibility within the field

- Retaining the copyright to your article

Submit your next manuscript at $\boldsymbol{\nabla}$ springeropen.com 